Document downloaded from:

http://hdl.handle.net/10251/57537

This paper must be cited as:

Galindo Lucas, J.; Climent Puchades, H.; Pla Moreno, B.; Jimenez Macedo, VD. (2011). Correlations for Wiebe function parameters for combustion simulation in two-stroke small engines. Applied Thermal Engineering. 31:1190-1199.

doi:10.1016/j.applthermaleng.2010.12.020.

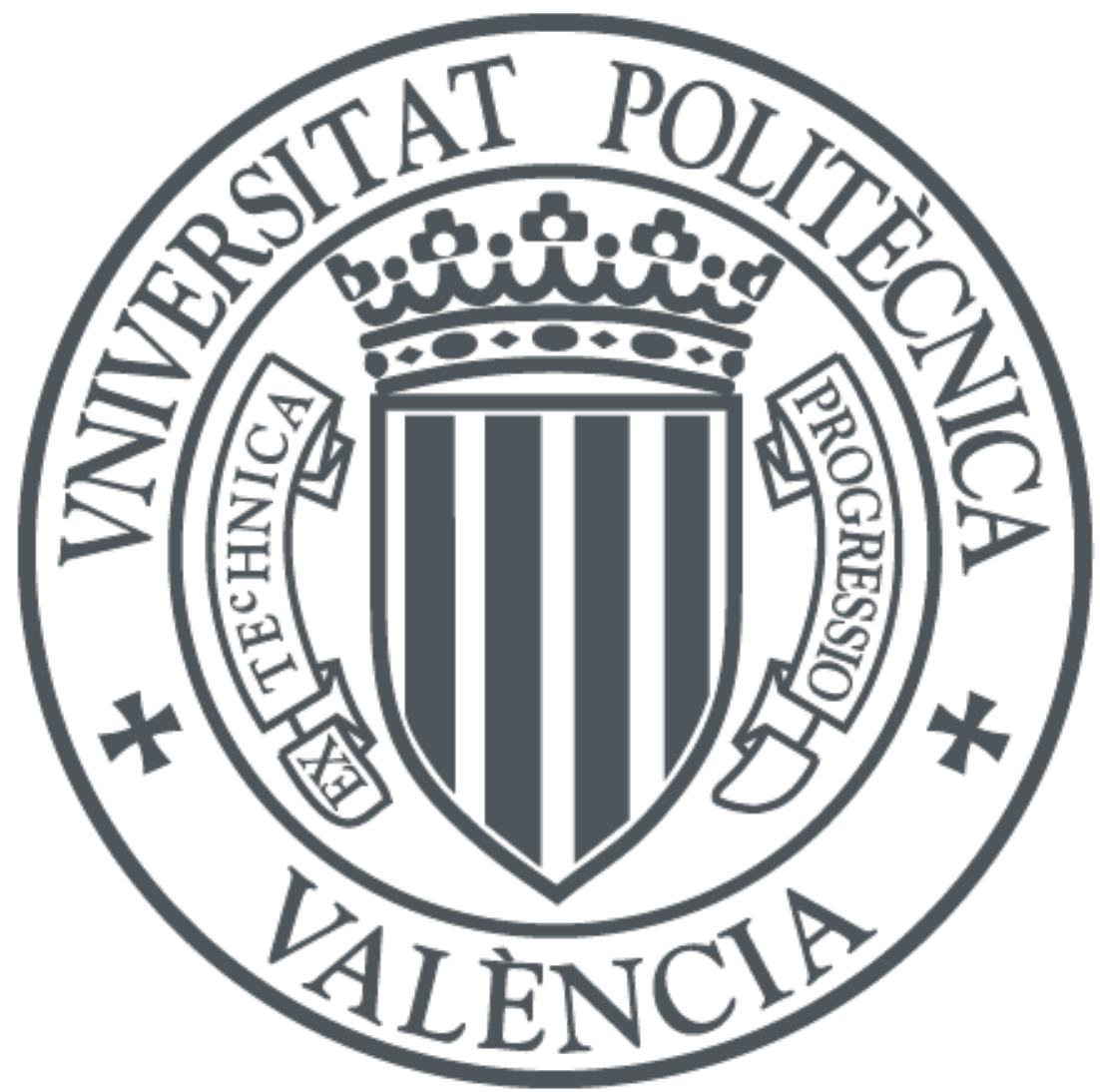

The final publication is available at

http://dx.doi.org/10.1016/j.applthermaleng.2010.12.020

Copyright Elsevier

Additional Information 


\title{
CORRELATIONS FOR WIEBE FUNCTION PARAMETERS FOR COMBUSTION SIMULATION IN TWO-STROKE SMALL ENGINES
}

\author{
J. Galindo, H. Climent, B. Plá, V.D. Jiménez \\ CMT - Motores Térmicos, Universidad Politécnica de Valencia, Spain \\ Camino de Vera s/n, E 46022, Valencia, Spain.
}

\begin{abstract}
Combustion simulation in two-stroke engines becomes necessary not only for engine performance prediction but also for scavenge evaluation, since in-cylinder pressure and temperature are highly influenced by combustion process evolution. Combustion simulation by using a Wiebe function is appropriate to be included in a 1D engine code for providing design criteria with fast and accurate calculations; the main drawback is the determination of the four Wiebe parameters needed to build up the in-cylinder heat release.

This paper deals with a detailed methodology for heat release determination in two-stroke engines under wide range of running conditions; obtained empirical data will serve for building ad-hoc Wiebe functions, whose four parameters will be finally correlated with engine related parameters derived from 1D simulations. Two different engines, with three exhaust systems each, varying engine speed and spark ignition timing were used to obtain correlations far from particular situations.
\end{abstract}

A multiple regression analysis stated that charge density, residual gas fraction, spark timing and mean piston speed were the significant engine parameters that influence on Wiebe parameters. Finally, two scenarios were considered regarding Wiebe parameters: a) specific correlations different for each engine gave coefficient of multiple determination values higher than $98 \%$ when predicting indicated mean effective pressure, b) a global correlation used for both engines provided $\mathrm{R}^{2}$ values of $93 \%$ in the $50 \mathrm{cc}$ and $91 \%$ in the $125 \mathrm{cc}$ engine.

Key words: Two-stroke engine; phenomenological combustion model; Wiebe's function; HRR correlation

\section{INTRODUCCION}

Small two-stroke engines, which are widely used in mobile machinery, will have to accomplish strict anti-pollution standards in imminent years. Active and passive solutions applied to two- 
stroke engines design have arisen in the last decades. Conforming active solutions, exhaust emissions reduction technologies have been investigated [1-3], and on the other hand, within passive solutions, current engine systems with different technologies (carburettor, direct injection, catalyst) are being improved and evaluated in terms of emission control [4]. The use of computer simulations to aid engine systems design process has been largely applied and has become a popular tool because of combination of accurate results and reduced costs.

Combustion simulation in two-stroke engines becomes necessary not only for engine performance prediction but also for scavenge evaluation, since in-cylinder pressure and temperature are highly influenced by combustion process evolution. The cylinder blow-down, which is originated when the exhaust port opens and configures the exhaust port instantaneous pressure due to wave propagation phenomena inside the exhaust system, depends highly on in-cylinder conditions at exhaust port opening. Several approaches may be considered for combustion modelling. Enumerating in time consuming order one may find: computational fluid dynamics codes and quasi-dimensional combustion models on one side, and combustion empirical models on the other side. The former techniques allow a physical approach but provide large computational time and effort. Although their predictive capabilities, they are beyond the scope of this paper since they are not suitable for fast computer simulations within a wave action model scenerario. On the other hand, combustion simulation by using a Wiebe function [5] lacks of physical representation but is appropriate to be included in a 1D engine code. Although this second method is traditionally the most widely employed, the main drawback is the determination of the four Wiebe parameters needed to build up the in-cylinder of heat release rate (HRR).

HRR determination in four stroke engines is obtained solving the first law of Thermodynamics in the cylinder closed cycle with the aid of experimental information; mainly the instantaneous incylinder pressure [6]. More elaborated models integrate simulation of the open cycle to better capture the in-cylinder trapped mass [7]. In two stroke engines the open cycle is even more critical, since wave propagation phenomena inside the exhaust system influence greatly in the in-cylinder trapped mass [8] and transfer ports configuration plays an important role on the scavenge loop features and short-circuit phenomenon. Therefore, for HRR finding in two-stroke 
engines it is compulsory to solve both the closed and the open cycle if consistent results are desired.

Besides the HRR determination issue, which can be coped with empirical assistance and convenient use of theoretical models, Wiebe function parameters selection for simulations at different engine running conditions still remains unclear. Literature survey did not help on finding out ready-to-use correlations for these parameters in the frame of small two-stroke engines. Empirical functions $[9,10]$ were developed for the 0-90 per cent mass fraction burned angle and the factor form for a $1600 \mathrm{cc}$ four-stroke spark-ignition engine. Direct application of previously published functions provides Fig.1, where comparisons of burn angles and form factors are presented. Results show that both, burn angle and form factor, obtained with existing functions [10] do not correlate with enough accuracy with data obtained in this work. Therefore, it is necessary to develop new functions for small two-stroke engines, whose characteristics differ greatly from conventional four-stroke automotive engines mainly due to differences in engine speed and in-cylinder conditions during the combustion process.

Performance prediction models in two-stroke engines need this information for providing accurate and reliable results. In summary, this paper deals with a detailed methodology for HRR determination in two $2 \mathrm{~S}$ engines under wide range of running conditions; obtained empirical data will serve for building ad-hoc Wiebe functions, whose parameters will be finally correlated with engine related parameters derived from 1D simulations.

The paper is structured as follows. Section 2 is devoted to the description of the experimental facility used to gather empirical data. Section 3 contains the detailed methodology for HRR determination including a combustion diagnosis model and a 1D engine model. Results for the empirical correlations to be used for Wiebe parameters are given in Section 4. Analysis of the influence of relevant engine parameters to the correlations is also performed in this section. Finally, main conclusions of the present study are presented in Section 5.

\section{EXPERIMENTAL SETUP}

Two two-stroke engines, whose main features are shown in Table 1, were employed in the present study. Both units are spark-ignited, crankcase-scavenged type, single-cylinder engines. A test bench, shown schematically in Fig. 2, was fully instrumented to carry out performance 
and emissions measurements. Main measurement devices consisted of an eddy-current electric brake (up to $6 \mathrm{~kW}$ power when testing the $50 \mathrm{cc}$ and $175 \mathrm{~kW}$ for the $125 \mathrm{cc}$ engine), a hot wire anemometer to measure the air mass flow entering the engine, a gravimetric balance to register the fuel consumption and a Horiba Mexa 1300 exhaust gas analyzer to collect $\mathrm{HC}$, NO and CO emissions. Firing tests were carried out at different load and engine speed conditions, since an electronic module controlled the brake as well as the throttle position. Both engines have liquid cooled cylinders, so a second cooling system was designed and built in order to control the engine coolant temperature.

Fluid flow properties are also relevant in checking the accuracy of the model, which will be described in detail in Section 3.2. Therefore, mean temperature and pressure were measured at the intake and exhaust pipes with thermocouples and manometers. Moreover, pressure transducers were placed in the cylinder, crankcase, and exhaust port in order to measure the instantaneous evolution (every 0.5 crank angle degree).

Since the main objective of this work is to obtain Wiebe parameters correlations for combustion simulation, a representative sample of two-stroke engine running conditions is required. Performing measurements in two different engines at wide range of rotating speeds is one way to accomplish this. Another simple technique to greatly modify the behaviour of a two-stroke engine consists in changing the exhaust system. Therefore, three exhaust systems were employed for the $50 \mathrm{cc}$ engine, and also three units designed for the $125 \mathrm{cc}$ engine.

Schematic layouts of the exhaust systems are represented in Fig. 3 where basic geometrical data are detailed. Exhaust system modification in $125 \mathrm{cc}$ engine is achieved by adding a duct between the cylinder block and the exhaust pipe. Three configurations were attained: without duct, and with $65 \mathrm{~mm}$ and $100 \mathrm{~mm}$ length duct. Geometrical data of the exhaust systems for the $50 \mathrm{cc}$ engine are also shown in Fig. 3. All of them share the same geometry, however: exhaust system \#1 has a catalytic converter at the end of the tapered pipe, unit \#2 includes also a catalytic covering inside the divergent tapered pipe while the third exhaust system does not include any catalytic device. Fig. 4 shows the air mass flow through the engine in both engines, where large differences are detected when changing exhaust systems. Moreover, it was possible to modify the spark-ignition timing in the $50 \mathrm{cc}$ engine. So combining engine speed, 
exhaust system and spark-ignition timing gives 33 and 14 running conditions for the $50 \mathrm{cc}$ and 125 cc engines respectively.

\section{METHODOLOGY}

In this section the applied methodology to acquire the heat release rate of two-stroke engine operation is detailed. Well known cycle-to-cycle variation [11] is the first issue that has to be solved. The post-processing tasks that will lead to the HRR determination are later described. These tasks consist of two models that are solved iteratively until convergence is achieved: the combustion diagnostic model and the engine model. The combustion diagnostic model uses empirical information in order to obtain in-cylinder heat release rate, which is needed by the engine model. At the same time, the engine model provides in-cylinder trapped mass and residual gas fraction to the combustion diagnostic model. When the iterative process finishes, validation of measured and predicted results from the engine model is performed.

\subsection{Average cycle determination}

Dealing with cycle-to-cycle variation is beyond the scope of the present study. Instead, an average engine cycle will be considered as repetitive and characteristic of a specific engine running conditions. Fig. 5 presents the instantaneous pressure traces in the cylinder, in the crank-case and in the exhaust pipe, measured in the $50 \mathrm{cc}$ engine. Although these measurements are shown for the maximum power engine operation, variations in consecutive cylinder cycles are significant. Other engine running conditions reveal stronger effects due to the presence of high residual gases levels in the cylinder when the exhaust system is not tuned. Fortunately for 1D engine modelling purposes, as shown in Fig. 5, the cycle-to-cycle variations appear only in the cylinder pressure and are not translated to crank-case or exhaust pipe traces.

The procedure for the election of the average cycle is simple. In the engine test bench 100 consecutive cycles are registered. The indicated mean effective pressure (imep) is calculated for all of them. The cycle whose imep is closer to the average from those 100 cycles is the selected one. Measuring 100 cycles is not arbitrary. Fig. 6 shows the histograms for the $50 \mathrm{cc}$ engine at different engine speeds. It is observed that all of them behave like a normal distribution so 100 cycles is a representative sample to extract the average cycle. 


\subsection{Combustion diagnostic model description}

The in-cylinder pressure is measured with a piezoelectric transducer and sampled with constant angular frequency. The first law is applied between exhaust port closing and opening, considering the combustion chamber as a closed system since blow-by is neglected. It uses the ideal gas equation of state to calculate the mean gas temperature in the chamber. Along with the two basic equations, two submodels to calculate instantaneous volume and heat transfer are used. The main result is HRR.

The hypotheses of the combustion diagnosis model are: a) the pressure is uniform in the combustion chamber, which is valid when the fluid and flame propagation velocities are much smaller than sound speed [6]; b) the fluid in the chamber is considered a mixture of three gases: air, gasoline and burned gases; c) perfect gas behaviour is assumed for the gas mixture; d) correlations based on the temperature are used to calculate sensible internal energy of the gas mixture; e) the internal energy is calculated considering the mean gas temperature, which is the hardest hypothesis since burned products are hotter than mean temperature at the start of combustion, even though later they become closer; f) Annand's equation is used to calculate the heat transfer coefficient.

The instantaneous volume is the sum of the combustion chamber volume and the volume displaced by the piston (depending on crank angle), which is calculated by means of

$V=V_{c c}+\frac{\pi d_{c}^{2} s}{8} \cdot\left(\sqrt{\left(1+\frac{1}{\lambda}\right)^{2}-e^{2}}-\cos (\alpha)-\sqrt{\frac{1}{\lambda^{2}}-(\sin (\alpha)-e)^{2}}\right)$

where

$V_{c c}=\frac{V_{d}}{C R-1}$

being $C R$ the geometric engine compression ratio.

Concerning heat transfer estimation, the most extended approach considers convection and Annand [12] recommends the following expression to relate Reynolds and Nusselt numbers:

$$
N u=\mathrm{a} \mathrm{Re}^{0.7}
$$

where the constant $a$ is set to 0.26 for a two-stroke engine. The Reynolds number is calculated with the gas density and viscosity, the cylinder bore and the mean piston velocity: 
$\operatorname{Re}=\frac{\rho c_{m} d_{c}}{\mu}$

The convection heat transfer coefficient is extracted now from the Nusselt number, and knowing gas conductivity, using:

$h=\frac{k N u}{d_{c}}$

The instantaneous in-cylinder heat transfer can be calculated as

$\frac{\delta Q_{w}}{d t}=h\left[\left(T_{c}-T_{w, \text { liner }}\right) A_{\text {liner }}+\left(T_{c}-T_{w, \text { piston }}\right) A_{\text {piston }}+\left(T_{c}-T_{w, c y l-h e a d}\right) A_{c y l-h e a d}\right]$

where surface areas consist of the liner, the piston and the cylinder head, and wall temperatures are calculated by means of empirical correlations [13].

Finally, the first law of thermodynamics for a closed system can be reordered as follows:

$$
H R R=-p d V-\delta Q_{w}-m_{c} d u_{c}
$$

It is relevant to note that in-cylinder trapped mass, $m_{c}$, is an input to combustion diagnosis model and comes from calculations performed in an overall engine model, which is described in the following section.

The Wiebe function $[10,14]$ is a very convenient method to simulate fuel burning in internal combustion spark-ignition engines. The Wiebe function for the mass fraction burned is given by:

$$
X_{b}=1-e^{-a\left(\frac{\alpha-\alpha_{0}}{\Delta \alpha}\right)^{n}}
$$

where $\alpha, \alpha_{0}$ and $\Delta \alpha$ are the instantaneous crank angle, the start of combustion crank angle, and the combustion angle, respectively. In this expression, $a$ and $m$ are tuning parameters. Since the a coefficient represent the combustion efficiency, in the present work it has been fixed to 6.9 , so that, $99.9 \%$ of the fuel is burnt when the combustion has finished. The derivative of Equation (8) should equal the HRR determined in Equation (7), so:

$$
H R R=\frac{a(m+1)}{\Delta \alpha}\left(\frac{\alpha-\alpha_{0}}{\Delta \alpha}\right)^{n-1} e^{-a\left(\frac{\alpha-\alpha_{0}}{\Delta \alpha}\right)^{n}}
$$

Lastly, final step leads to select convenient Wiebe parameters to provide a match with experimental information. 
In an SI engine with a limited compression ratio, the mixture temperature may not rise to a sufficient level to generate auto-ignition, at the end of the compression stroke [15]. Ignition delay was chosen to be half the spark ignition advance. Fig. 7 shows an example of the HRR obtained with the presented methodology and the modelled Wiebe function. Results correspond to the $50 \mathrm{cc}$ engine at $6000 \mathrm{rpm}$ open throttle.

\subsection{Engine model description}

Wave propagation phenomena during gas exchange processes inside internal combustion engines are assumed to be one-dimensional. In the case under consideration, a wave action model, which solves the unsteady, non-linear and one-dimensional flow equations using a finite difference scheme [16], was used to model both two-stroke engines.

These engines are composed basically of three kinds of elements: ducts, volumes and junctions. Volumes (such as cylinder, crank-case, airbox and atmosphere) are calculated using a zero dimensional approach, by solving mass and energy conservation equations. In-cylinder HRR, via Wiebe function, is an input to this model since information coming from the combustion diagnosis model is provided. Effective area of connections (such as exhaust and transfer ports, rotating disk or reed valves) between ducts and volumes are solved by means of a discharge coefficient, which has to be previously obtained in a steady flow bench. Boundary conditions are solved using the method of characteristics and then coupled with the finite difference calculation in the ducts $[17,18]$. Exhaust systems, silencer and airbox were characterized in an impulse test rig [19]; subsequently they were simulated individually with the 1D code, for later construction of the complete geometry.

The governing equations that describe the one-dimensional non-homentropic gas flow, with the consideration of area change, friction and heat transfer in a pipe, form a non-homogenous hyperbolic system, and are represented in vector notation as [20]:

$\frac{\partial \mathbf{W}}{\partial t}+\frac{\partial \mathbf{F}}{\partial x}+\mathbf{C}_{1}+\mathbf{C}_{2}=0$

This conservation law system, comprising the continuity, momentum and energy equations, is complemented by the equation of state or the real gas properties [21]. In Equation (10), $\mathbf{W}$ is the desired state vector of the solution, $\mathbf{F}$ is the flux vector and $\mathbf{C}$ the source term separating the 
effect of the area changes from the effect of friction and heat transfer. The one-dimensional gas flow governing equations was traditionally arranged in the vector form shown in Equation (11):

$\mathbf{W}(x, t)=\left[\begin{array}{c}\rho \\ \rho u \\ \rho \frac{u^{2}}{2}+\frac{p}{\gamma-1}\end{array}\right]$

$$
\mathbf{F}(\mathbf{W})=\left[\begin{array}{c}
\rho u \\
\rho u^{2}+p \\
u\left(\rho \frac{u^{2}}{2}+\frac{\gamma p}{\gamma-1}\right)
\end{array}\right]
$$

$\mathbf{C}_{1}(x, \mathbf{W})=\left[\begin{array}{c}\rho u \\ \rho u^{2} \\ u\left(\rho \frac{u^{2}}{2}+\frac{\gamma p}{\gamma-1}\right)\end{array}\right] \frac{1}{S} \frac{d S}{d x} \quad \mathbf{C}_{2}(\mathbf{W})=\left[\begin{array}{c}0 \\ g \rho \\ -q \rho\end{array}\right]$

This set of equations is solved by using the two-step Lax-Wendroff method [22], which is programmed in the computer code together with the boundary conditions. Scavenging process is an important issue in two-stroke engines [23]. A well-known model [13] to account for shortcircuit phenomenon was used in the present study.

\section{RESULTS AND DISCUSSION}

Application of the methodology presented in previous section to 47 engine running conditions (depending on engine size, exhaust system, engine speed and spark-ignition timing) results in a database where every sample consists of the following fields: (i) the four Wiebe parameters (tuned to match experimental HRR), (ii) mean piston speed and spark-ignition timing (fixed during engine tests) and, (iii) charge density at spark timing and residual gas fraction (obtained from engine simulations). Moreover, instantaneous pressure traces can be compared in every running condition to check model capabilities.

Comparison between measured and calculated results is shown in Fig. 8 at $50 \mathrm{cc}$ engine full load and $6000 \mathrm{rpm}$. Predicted instantaneous pressure in the exhaust port presents good agreement. Therefore, it can be assumed that the wave action model calculates with accuracy the fluid dynamics inside tapered pipes with unsteady and high temperature flow conditions. Crankcase pressure is also well captured, although measurements show high frequency content due to the additional length of the duct that was necessary to insert when placing the pressure transducer in the engine. Predicted in-cylinder pressure is very similar to measured one since ad-hoc parameters are used in the Wiebe function for HRR estimation. 
Application of a multiple regression analysis between Wiebe's function parameters (combustion angle and form factor) and engine related parameters such as mean piston speed, charge density and trapped residual gas fraction gives the following results. If correlations are obtained taking into account that the selected engines operation differ from one to another then two sets of correlations arise. Equation (12) provides a correlation for combustion angle and form factor for the 50 cc engine:

$$
\begin{gathered}
\Delta \alpha=110\left(\frac{1}{\rho_{S T}}\right)^{0.34}\left(1-\frac{0.8}{\sqrt{c_{m}}}\right)\left(\frac{1}{1-1.98 x_{r}^{0.46}}\right)^{0.85}\left(0.00032 \alpha_{S T}^{2}-0.026 \alpha_{S T}+1\right) \\
n=1.37\left(\frac{1}{\sqrt{c_{m}}}\right)^{0.25}\left(\frac{1}{1+\sqrt{\alpha_{S T}}}\right)^{-0.53}\left(1+4.94 x_{r}\right)
\end{gathered}
$$

Similarly, equation (13) corresponds to the $125 \mathrm{cc}$ high performance engine:

$$
\begin{gathered}
\Delta \alpha=85\left(\frac{1}{\rho_{S T}}\right)^{0.34}\left(1-\frac{0.8}{\sqrt{c_{m}}}\right)\left(\frac{1}{1-2.14 x_{r}^{0.46}}\right)^{0.85}\left(0.00051 \alpha_{S T}^{2}-0.02 \alpha_{S T}+1\right) \\
n=1.37\left(\frac{1}{\sqrt{c_{m}}}\right)^{0.25}\left(\frac{1}{1+\sqrt{\alpha_{S T}}}\right)^{-0.45}\left(1+6.9 x_{r}\right)
\end{gathered}
$$

Previous equations consist of a dimensional constant and a set of functions which are assumed to have an independent effect on each Wiebe parameter. Constants on equations are given when charge density is in $\mathrm{kg} / \mathrm{m}^{3}$, mean piston speed in $\mathrm{m} / \mathrm{s}$, residual gas fraction is dimensionless, and spark timing is in crank-angle degrees before TDC.

One-dimensional computer simulations using previous correlations were performed. Fig. 9 shows the comparison between calculated and measured indicated mean effective pressure for the $50 \mathrm{cc}$ (top plot) and $125 \mathrm{cc}$ (bottom plot). Results include the simulation of the exhaust systems at wide engine speed ranges mentioned in Section 2. For the $50 \mathrm{cc}$ engine, different spark ignition timing simulations are also included. The coefficient of multiple determination $\left(R^{2}\right)$ is higher than $98 \%$ for both engines.

Global correlations for combustion angle and form factor are obtained at this point. The main aim is to check the lack of accuracy when predicting engine performance if no ad-hoc correlations are available for a specific engine. If the multiple regression analysis is performed using both engines data, the correlations are represented in Equation (14). 


$$
\begin{gathered}
\Delta \alpha=97\left(\frac{1}{\rho_{S T}}\right)^{0.34}\left(1-\frac{0.8}{\sqrt{c_{m}}}\right)\left(\frac{1}{1-2.06 x_{r}^{0.46}}\right)^{0.85}\left(0.0004 \alpha_{S T}^{2}-0.024 \alpha_{S T}+1\right) \\
n=1.37\left(\frac{1}{\sqrt{c_{m}}}\right)^{0.25}\left(\frac{1}{1+\sqrt{\alpha_{S T}}}\right)^{-0.48}\left(1+6.3 x_{r}\right)
\end{gathered}
$$

Finally, calculated and measured indicated mean effective pressure are compared in Fig. 10 (50 cc engine in top and $125 \mathrm{cc}$ in bottom plot). When global correlations are applied, the coefficient of multiple determination $\left(R^{2}\right)$ reduces to $93 \%$ for the $50 \mathrm{cc}$ and to $91 \%$ for the $125 \mathrm{cc}$ engine.

Same information as in Fig. 9 and Fig. 10 are given in Fig. 11 but presented in a different way. Measured and predicted engine performance is compared in a set of plots. Left and middle plots correspond to the $50 \mathrm{cc}$ engine results while right plots are for the $125 \mathrm{cc}$. The difference between left and middle plots is the engine spark timing. The difference between upper, middle and lower plots is the exhaust system used in the engine tests. As observed in the plots, when the exhaust system is changed, wave propagation phenomena produce optimum engine performance at different engine speeds. Therefore it is a convenient way to increase the number of cases for a larger database.

If specific combustion angle and form factor correlations are used for each engine (Eq. (12) for the $50 \mathrm{cc}$ and Eq. (13) for the $125 \mathrm{cc}$ engine), errors at imep predictions are lower than $5 \%$ for all the simulations. If the global correlation (Eq. (14)) is used for both engines simulations, errors in most of model predictions do not exceed $5 \%$ and the rest are lower than $10 \%$.

An important issue when working with correlations is, not only a high coefficient of multiple determination, but also their capability to represent physical phenomena in order to extend their use to similar engines or to other engine modifications. Correlations obtained in previous equations (12), (13) and (14) show multiplicative terms for the independent variables. Fig. 12 shows the four functions that influence on combustion angle correlation found in Eq. (14). Charge density function is consistent with reported results [10], where lower combustion angles are attained when increasing charge density at spark timing. A wide range of charge density values are achieved during engine testing which provides good samples for the database population. Since combustion angle is represented in terms of crank angle degrees, it is obvious that higher mean piston speeds conduct to an increase of combustion angle due to the fact that 
combustion timing is not heavily affected by engine speed. This effect is also shown in Fig. 12 and, again, a wide range of mean piston speeds were tested so as to obtain a large population. Spark timing on the $50 \mathrm{cc}$ could be easily changed. However, in the $125 \mathrm{cc}$ unit, spark timing variation was not possible and it was conveniently chosen by the ECU. Nevertheless, large variations in the spark timing were acquired in order to take it to the limits avoiding piston seizure. At high values of spark timing, although in-cylinder pressure and temperature are lower, the main part of the combustion process takes place near the TDC, which produces higher pressure and temperature evolutions and reduces combustion angle, as depicted in Fig. 12. Finally, it is well established that high trapped burn gas fraction leads to a slower combustion process and hence, to high values of combustion angle as residual gas fraction function represents in Fig. 12.

\section{CONCLUSIONS}

One-dimensional computer simulations require information concerning the combustion process, i.e. the heat release rate, which is usually represented in gasoline engines with a Wiebe function. A methodology that includes experimental and modelling tasks was proposed to acquire the HRR in two-stroke small engines. The methodology was applied to a $50 \mathrm{cc}$ and a $125 \mathrm{cc}$ engines for generalization purposes. Among other engine related parameters, in-cylinder pressure was measured and used in a combustion diagnostic model. Since the in-cylinder trapped mass is employed by this model, a 1D model was developed in order to capture wave propagation phenomena in exhaust and intake systems, and reproduce the scavenge process. Comparison of instantaneous pressure traces in the exhaust port, in the crank-case and in the cylinder while the scavenge process takes place proves that trapped mass was correctly predicted.

HRR were obtained under an extensive range of engines operation by modifying the exhaust system, engine speed and spark timing. The four parameters that build up the Wiebe function were tuned to capture each HRR resulting in a database together with engine related values. Some engine information was obtained directly from engine testing (such as engine speed or spark timing) while other was acquired by using the 1D engine model (such as charge density and residual gas fraction). A multiple regression analysis stated that charge density, residual 
gas fraction, mean piston speed and spark timing were the significant engine parameters that influence on Wiebe parameters.

Moreover, all the obtained correlations present a physical meaning related to the terms of the independent variables for the variation of both, combustion angle and form factor. Increasing charge density or spark timing (with reference to TDC) reduce combustion angle. High mean piston speed or gas residual fraction leads to higher combustion angle.

Finally, two scenarios were considered regarding the combustion angle and form factor: a) specific correlations for these parameters different for each engine, Eq. (12) for the $50 \mathrm{cc}$ and Eq. (13) for the $125 \mathrm{cc}$ engine, gave coefficient of multiple determination $\left(R^{2}\right)$ values higher than $97 \%$ when predicting indicated mean effective pressure, b) a global correlation used for both engines, Eq. (14), provided $R^{2}$ values of $93 \%$ in the $50 \mathrm{cc}$ and $91 \%$ in the $125 \mathrm{cc}$ engine.

\section{REFERENCES}

[1]. P. Duret, A. Ecomard, M. Audinet, A new two-stroke engine with compressed air assisted fuel injection system for high efficiency low emissions applications, SAE Paper 880176, 1988.

[2]. M. Nuti, R. Pardini, D. Caponi, Fast injection system: PIAGGIO solution for ULEV 2T SI engines, SAE Paper 970362, 1997.

[3]. F. Payri, J. Galindo, H. Climent, J.M. Pastor, C. Gaia, Optimisation of the scavenging and injection processes of an air-assisted direct fuel injection 50cc 2-stroke S.I. engine by means of modelling, SAE Paper 2001-01-1814, 2001.

[4]. J. Czerwinski, P. Compte, F. Reutimann, A. Mayer, Influencing (nano)Particle Emissions of 2-Stroke Scooters, International Journal of Automotive Technology 7(N3) (2006) 237244.

[5]. I. Wiebe, Halbempirische Formel für die Verbrennung-Geschwindigkeit, Verlag de Akademic der Wissenschaften der VdSSR 1956.

[6]. M. Lapuerta, O. Armas, J.J. Hernandez, Diagnosis of DI Diesel combustion from incylinder pressure signal by estimation of mean thermodynamic properties of the gas, Applied Thermal Engineering 19 (1999) 513-529.

[7]. F. Payri, S. Molina, J. Martín, O. Armas, Influence of measurement errors and estimated parameters on combustion diagnosis, Applied Thermal Engineering 26 (2006) 226-236. 
[8]. J. Galindo, J.R. Serrano, H. Climent, A. Tiseira, Analysis of gas-dynamic effects in compact exhaust systems of small two-stroke engines, International Journal of Automotive Technology 8(N4) (2007) 403-411.

[9]. F. Lindström, H. Angstrom, G. Kalghati, C. Moller, An empirical SI combustion model using laminar burnig velocity correlations, SAE Paper 2005-01-2106, 2005.

[10]. F. Bonatesta, B. Waters, P. J. Shayler, Burn angles and form factors for Wiebe function fits to mass fraction burned curves of a spark ignition engine with variable valve timing, International Journal of Engine Research 11(2) (2010) 177-186.

[11]. N. Ozdor, M. Dulger, E. Sher, Cyclic Variability in Spark Ignition Engines A Literature Survey, SAE Paper 940987, 1994.

[12]. W.J.D. Annand, T.H. Ma, Instantaneous Heat Transfer Rates to the Cylinder Heat Surface of a Small Compression Ignition Engine, Proc. IMech.E. 185 (1970-71) 976-987.

[13]. G.P. Blair, Design and simulation of two-stroke engines, R-161 Society of Automotive Engineers, Inc. Warrendale, PA. 1995.

[14]. J.R. Serrano, H. Climent, C. Guardiola, P. Piqueras, Methodology for characterisation and simulation of turbocharged diesel engines combustion during transient operation. Part 2: Phenomenological combustion simulation, Applied Thermal Engineering 29 (2009) $150-158$

[15]. J. Wijesinghe, G. Hong, Study of the autoignition combustion operating region of a small two-stroke engine, Proc. IMech.E. Part D: Journal of Automobile Engineering 223 (2009) 651-659.

[16]. F. Payri, J. Benajes, M.D. Chust, Programme pour étude assistée par ordinateur de systèmes d'admission et d'échappement de moteurs, Entropie 162 (1991) 17-23.

[17]. J.S. Chiou, M.S. Chiang, C.K. Chen, Numerical simulation method applied to the multiexpansion exhaust system of a two-stroke engine, Proc. IMech.E. Part D: Journal of Automobile Engineering 208 (1994) 281-288.

[18]. F. Payri, J.M. Desantes, A.J. Torregrosa, Acoustic boundary condition for unsteady onedimensional flow calculations, Journal of Sound and Vibration 188(N1) (1995) 85-110. 
[19]. F. Payri, J.M. Desantes, A. Broatch, Modified impulse method for the measurement of the frequency response of acoustic filters to weakly non-linear transient excitations, Journal of the Acoustical Society of America 107(N2) (2000) 731-738.

[20]. H. Daneshyar, One-Dimensional Compressible Flow, Pergamon Press (1976) ISBN 0080204139

[21]. D.E. Winterbone, R.J. Pearson, A Solution of the Wave Equations Using Real Gases, International Journal of Mechanical Sciences 34(N12) (1992) 917-932.

[22]. R.D. Richtmayer K.W. Morton, Difference Methods for Initial-Value Problems, Interscience, 1967.

[23]. M. Čudina, Model testing the two-phase scavenging system in a two-stroke petrol engine, Proc. IMechE Part D: Journal of Automobile Engineering 218 (2004) 1307-1316. 


\begin{tabular}{||l||l|l||}
\hline \multicolumn{3}{|c||}{ Engines main characteristics } \\
\hline \hline Engine displacemen & $50 \mathrm{~cm}^{3}$ & $125 \mathrm{~cm}^{3}$ \\
\hline Cylinders & 1 & 1 \\
\hline Bore & $39.88 \mathrm{~mm}$ & $54 \mathrm{~mm}$ \\
\hline \hline Stroke & 40 & $54.5 \mathrm{~mm}$ \\
\hline \hline Transfer ports & 5 & 5 \\
\hline \hline Exhaust ports & 1 (+2) & 1 (+2) \\
\hline Transfer ports opening & 120 @ATDC & 113 @ATDC \\
\hline \hline Exhaust ports opening & 94 @ATDC & 83 @ATDC \\
\hline Crankcase inlet control & Reed valve & Rotating disk \\
\hline \hline Fuel supply system & Carburettor & Carburettor \\
\hline \hline
\end{tabular}

Table 1. Engines main characteristics. 


\section{NOTATION LIST}

$\mathrm{C}_{\mathrm{m}}$ :mean piston speed

$\mathrm{C}_{\mathrm{p}}$ :specific heat at constant pressure $(\mathrm{J} / \mathrm{kg} \mathrm{K})$

$C R$ :compression ratio (-)

$d$ :diameter $(\mathrm{m})$

e:eccentricity $(m)$

$k$ :gas conductivity $(\mathrm{W} / \mathrm{m} \mathrm{K})$

Hc:heat of combustion $(\mathrm{J} / \mathrm{kg})$

Nu:Nusselt number (-)

p:pressure (bar)

u:velocity $(\mathrm{m} / \mathrm{s})$

R:ideal gas constant ( $/ \mathrm{kg} \mathrm{K})$

Re:Reynolds number (-)

s:stroke $(m)$

T:temperature $(\mathrm{K})$

V:volume $\left(\mathrm{m}^{3}\right)$

$x_{r}$ : residual gas fraction $(-)$

\section{ACRONYMS}

2S:two stroke

imep:Indicated Mean Effective Pressure

HRR:Heat Release Rate

GREEK SYMBOLS

$\alpha$ :crank angle degree $\left(^{\circ}\right)$

$\lambda$ :crank and connecting rod length ratio (-)

$\rho:$ gas density $\left(\mathrm{kg} / \mathrm{m}^{3}\right)$

$\mu$ :gas viscosity $(\mathrm{kg} / \mathrm{ms})$

SUBSCRIPTS

c:cylinder 
cc:combustion chamber

$\mathrm{d}$ :displacement

ST:spark timing

w:wall 

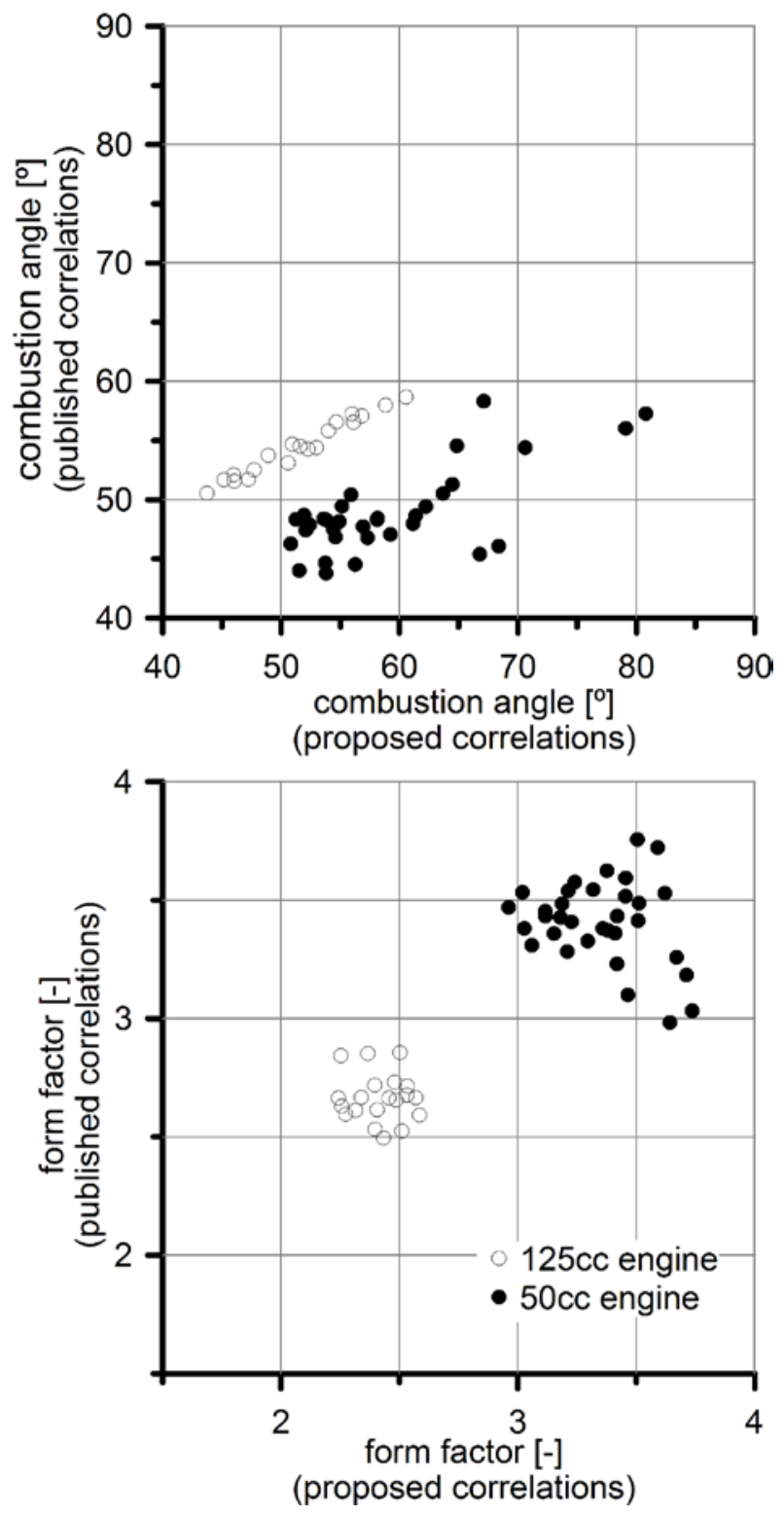

Fig 1. Comparison between published [10] and proposed combustion angle and form factor.

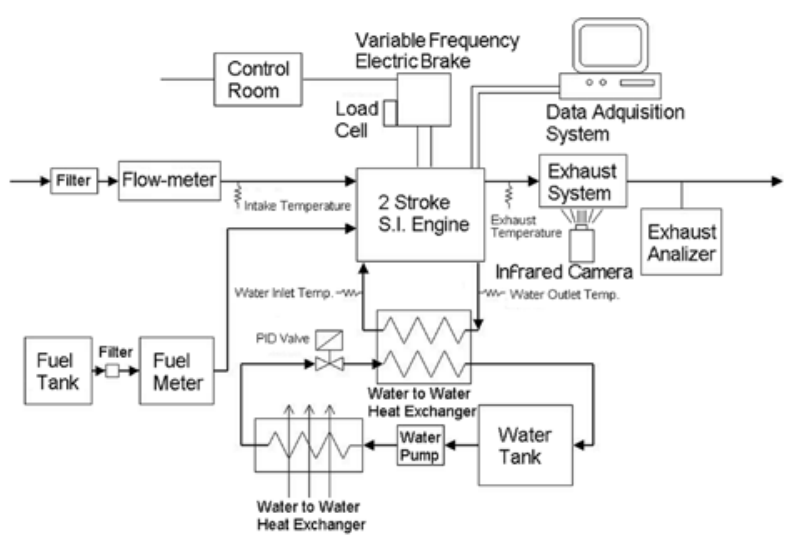

Fig 2. Schematic engine test bench layout. 

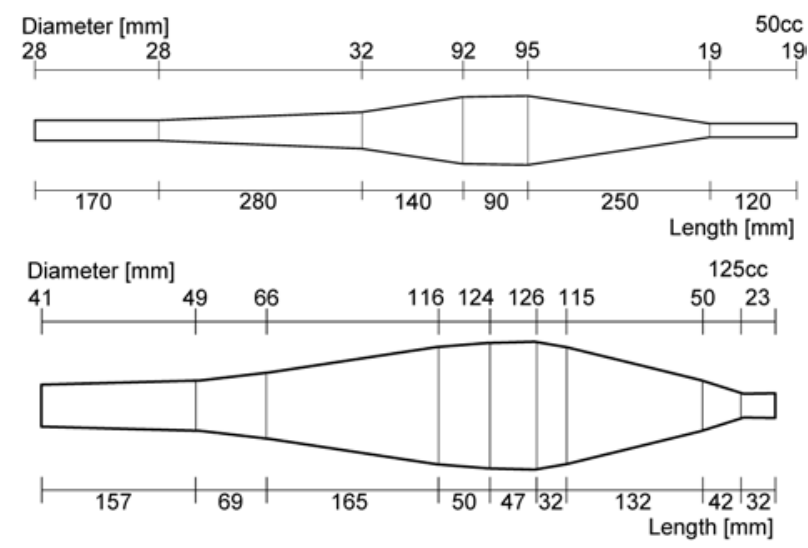

Fig 3. Schematic layout of the $50 \mathrm{cc}$ and $125 \mathrm{cc}$ engines exhaust systems.
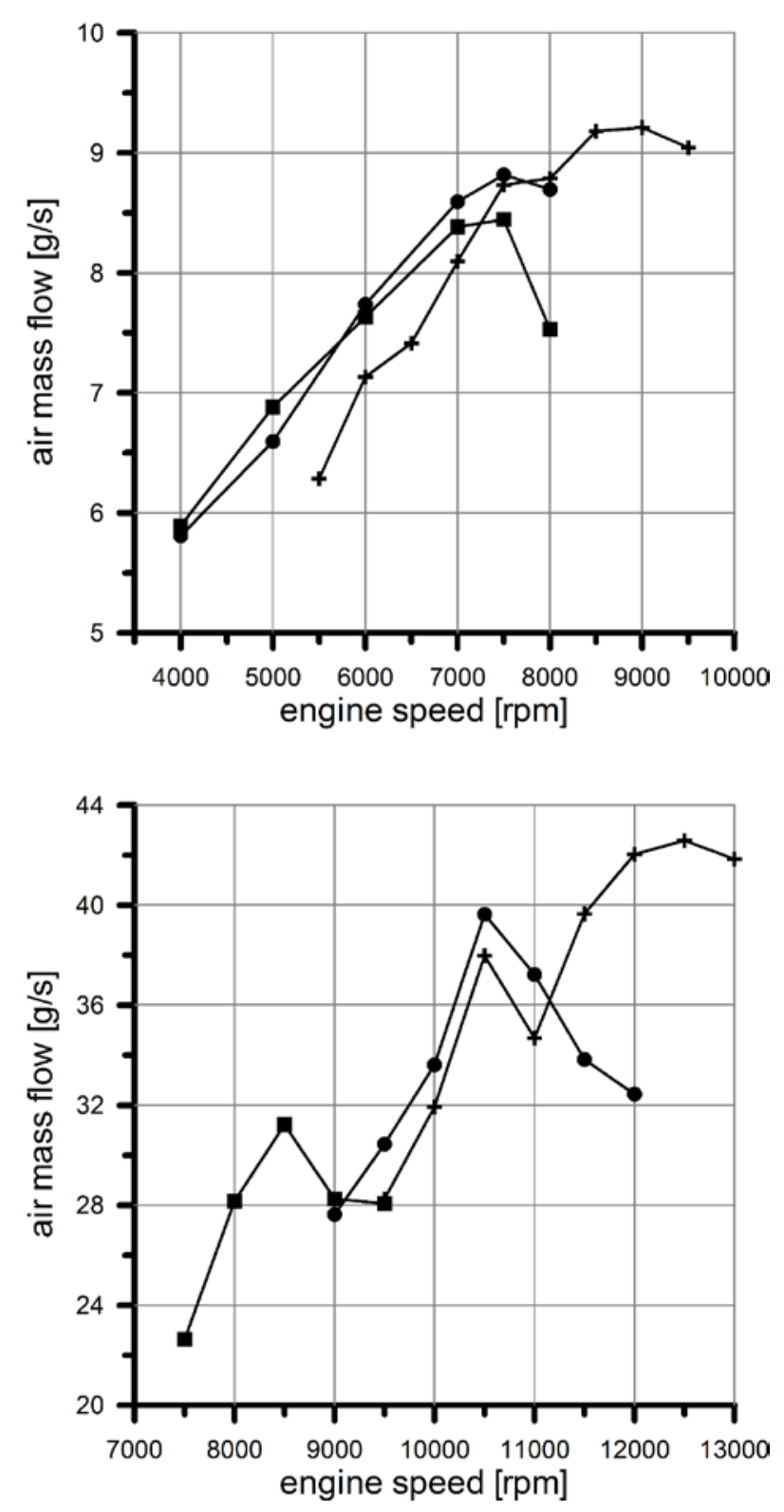
Fig 4. Measured air mass flow (50cc engine: top; $125 \mathrm{cc}$ engine: bottom).

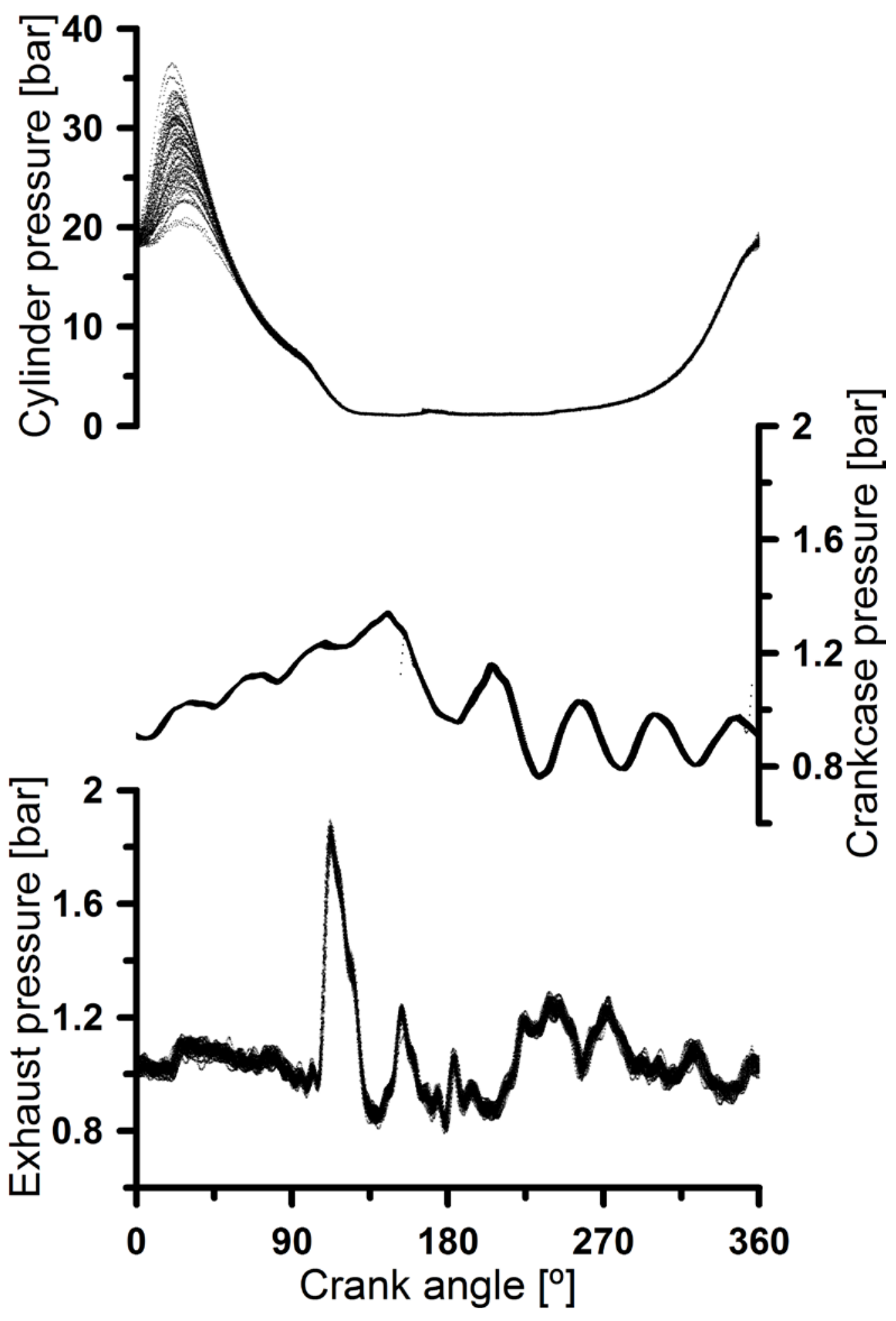

Fig 5. Cycle-to-cycle demonstration (50cc engine open throttle $6000 \mathrm{rpm}$; in-cylinder: top, crankcase: middle, exhaust port: bottom). 

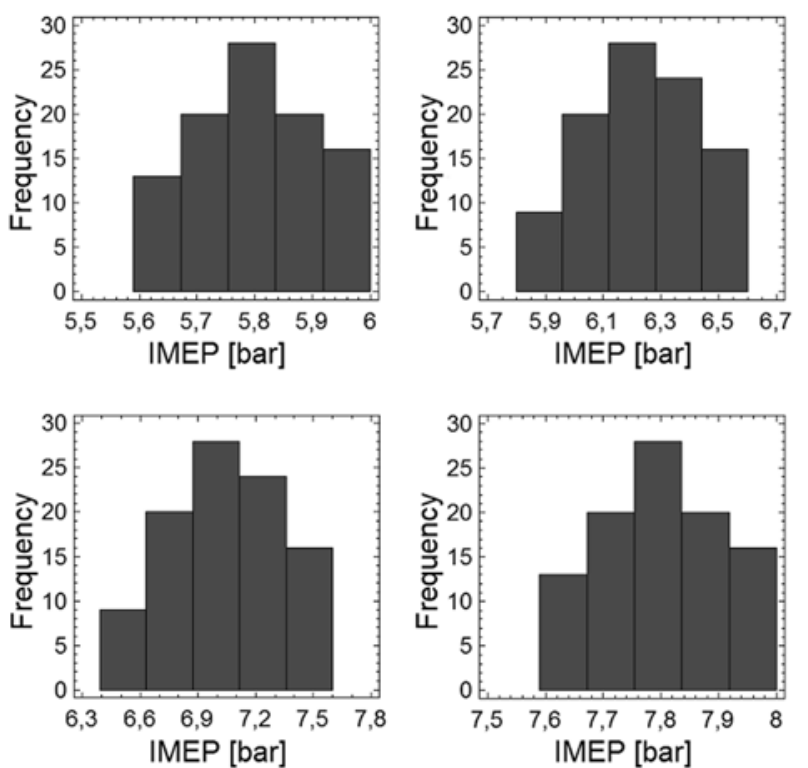

Fig 6. The frequency of distribution of imep in $50 \mathrm{cc}$ engine (5000 rpm: top left, $6000 \mathrm{rpm}$ : top right, 7000 rpm: bottom left, 8000 rpm: bottom right).

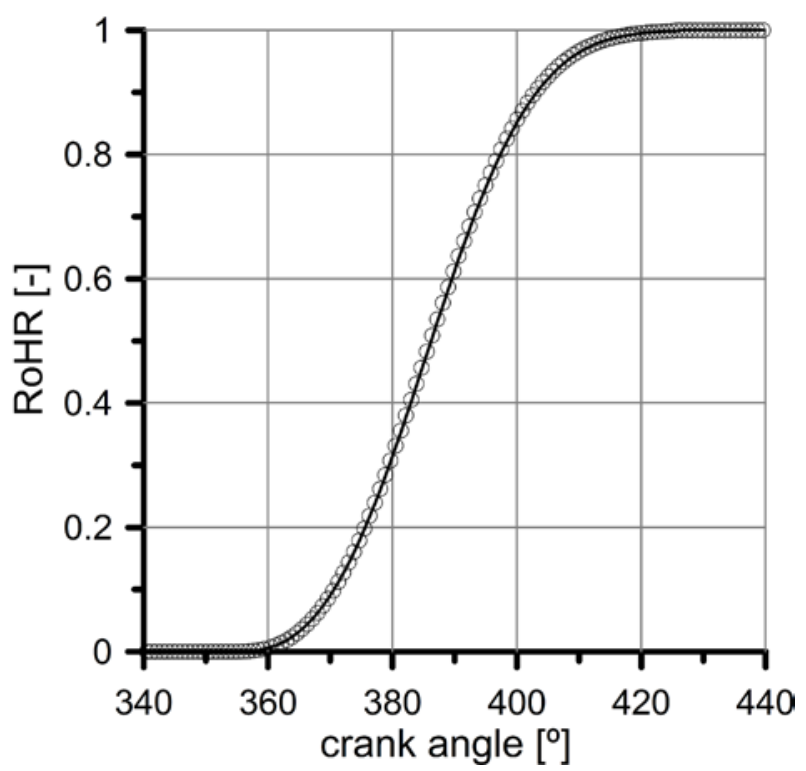

Fig 7. Measured burned mass fraction and matched Wiebe's function. 


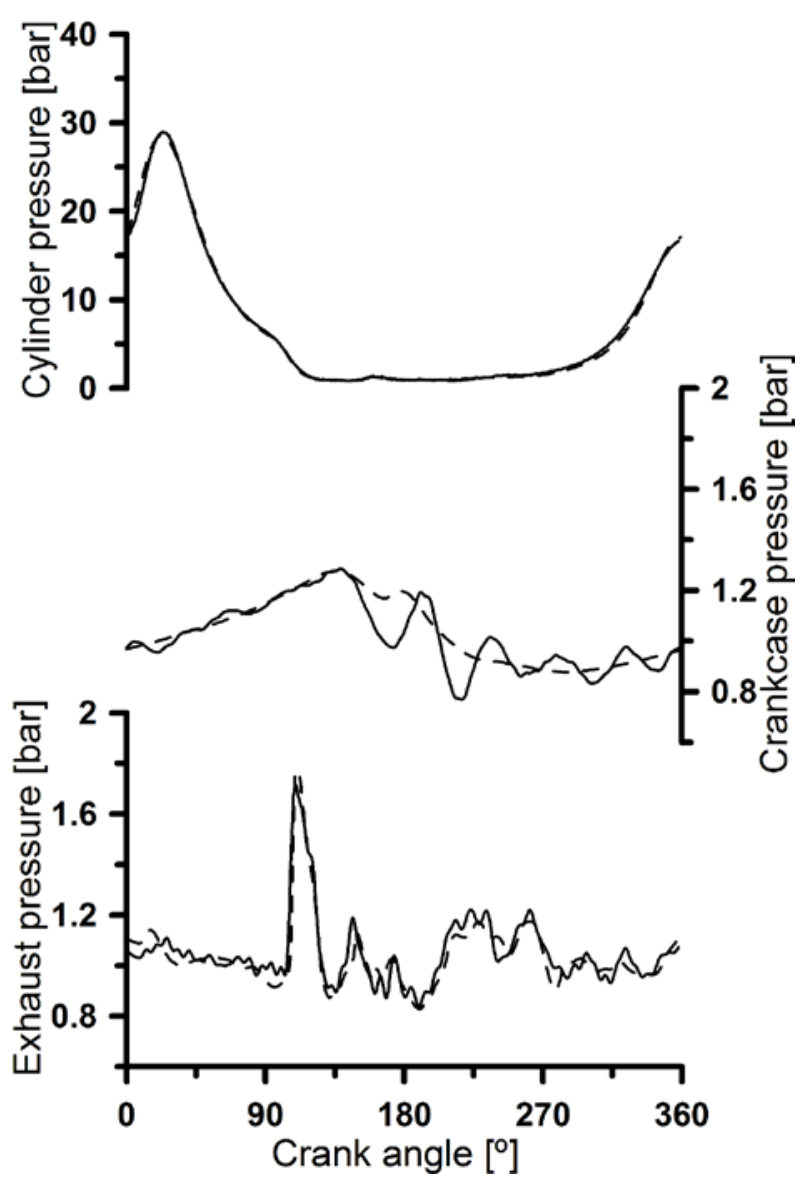

Fig 8. Measured and calculated instantaneous pressure results (50cc engine open throttle 6000 rpm; in-cylinder: top, crankcase: middle, exhaust port: bottom). 

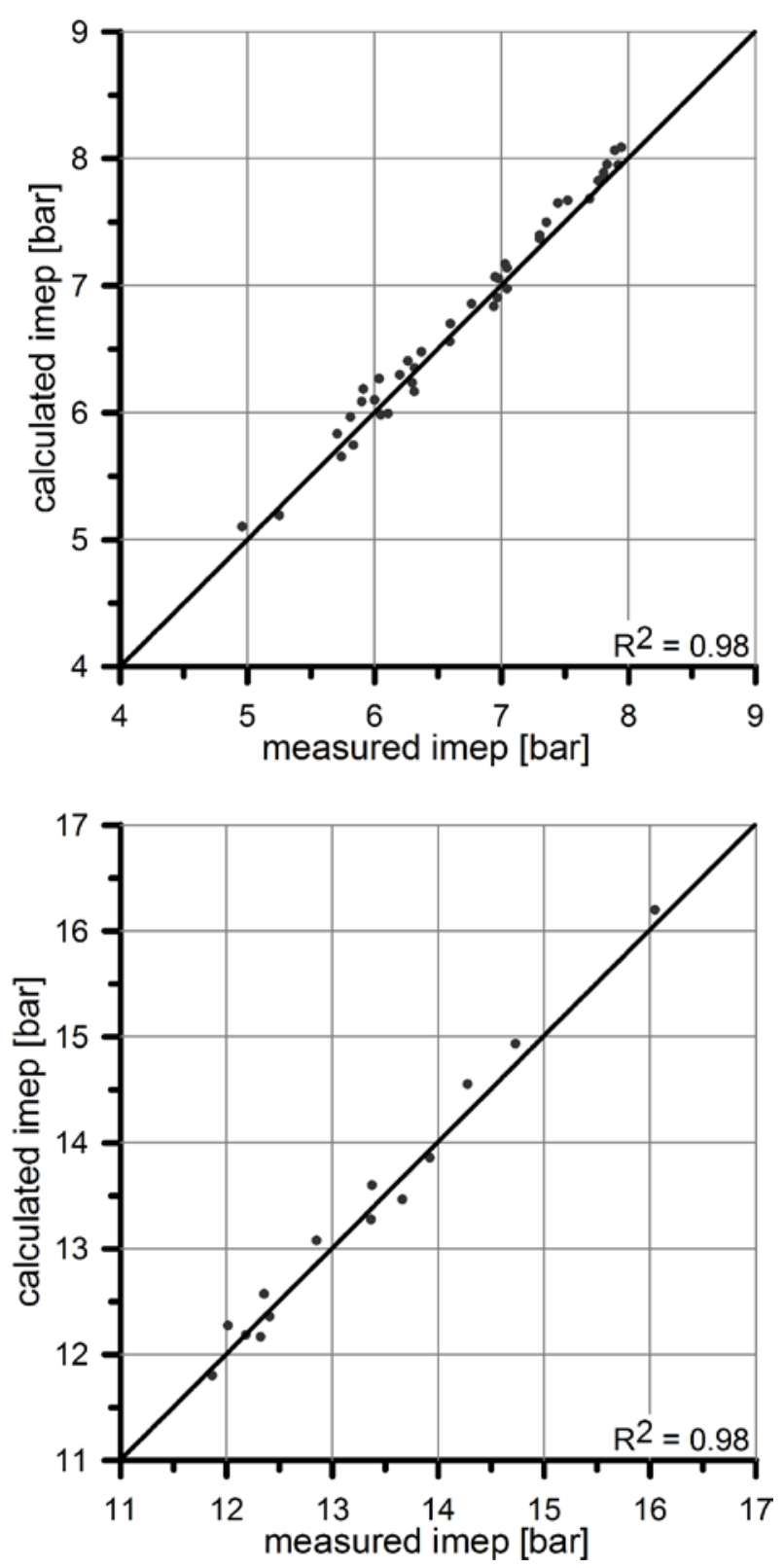

Fig 9. Measured and calculated imep (50cc engine with correlations in Eq. (12): top, 125cc engine with correlations in Eq. (13): bottom). 

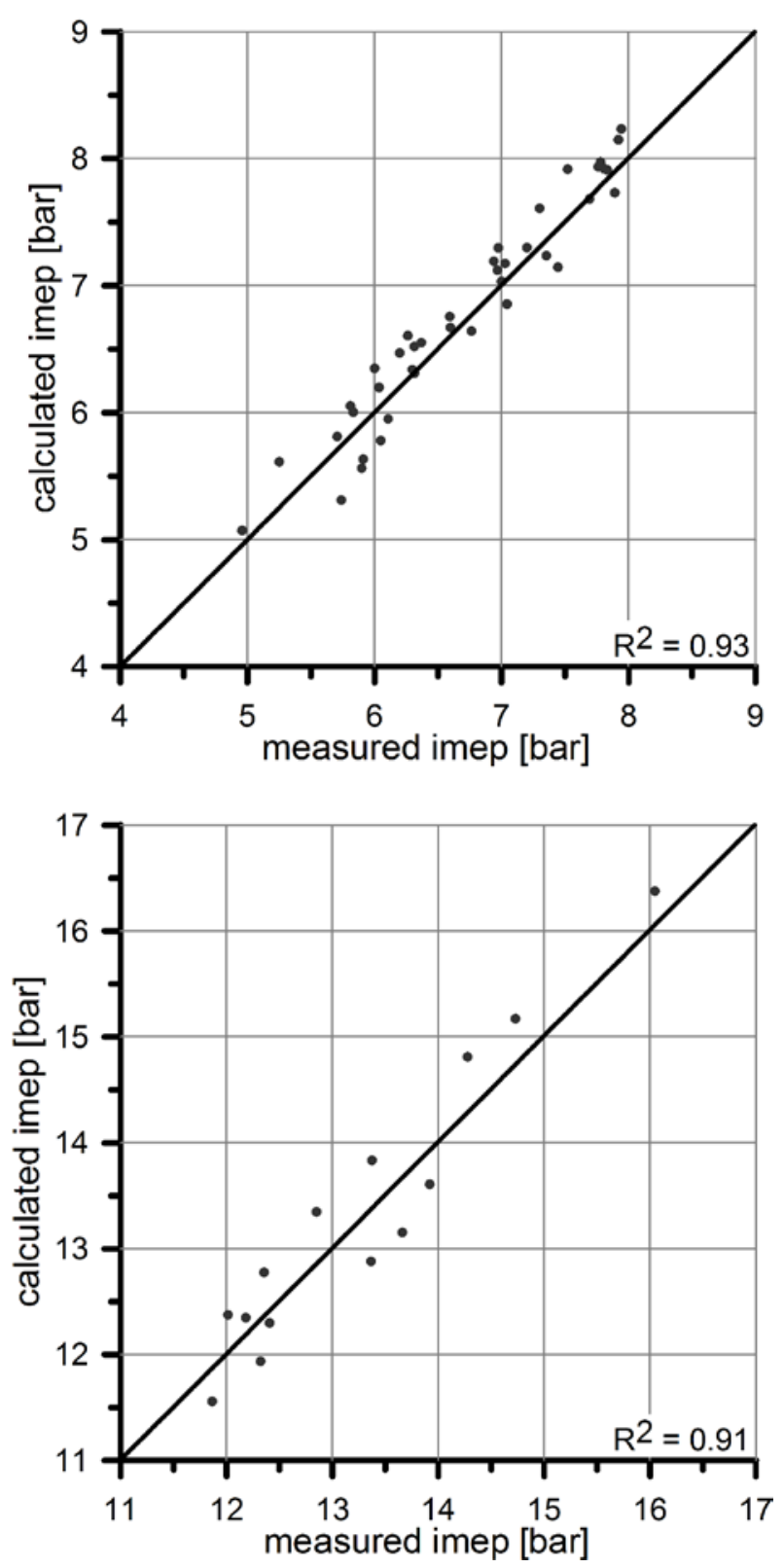

Fig 10. Measured and calculated imep with correlations in Eq. (14) (50cc engine: top, 125cc engine: bottom). 

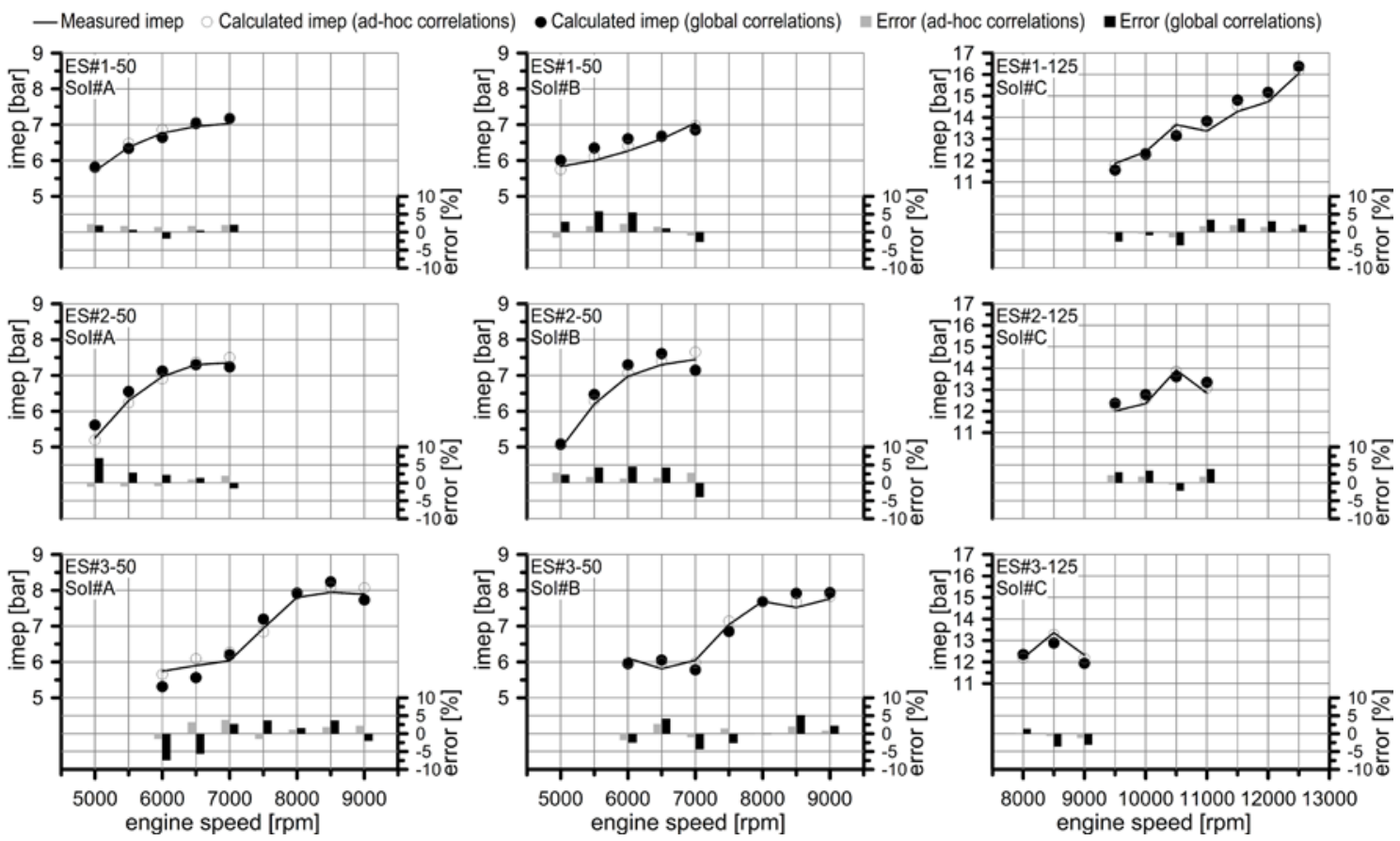

Fig 11. Engines performance: measured and calculated imep with correlations in Eq. (12), Eq.

(13) and Eq. (14) (50cc engine: left and middle, 125cc engine: right; using different exhaust systems and spark timings).
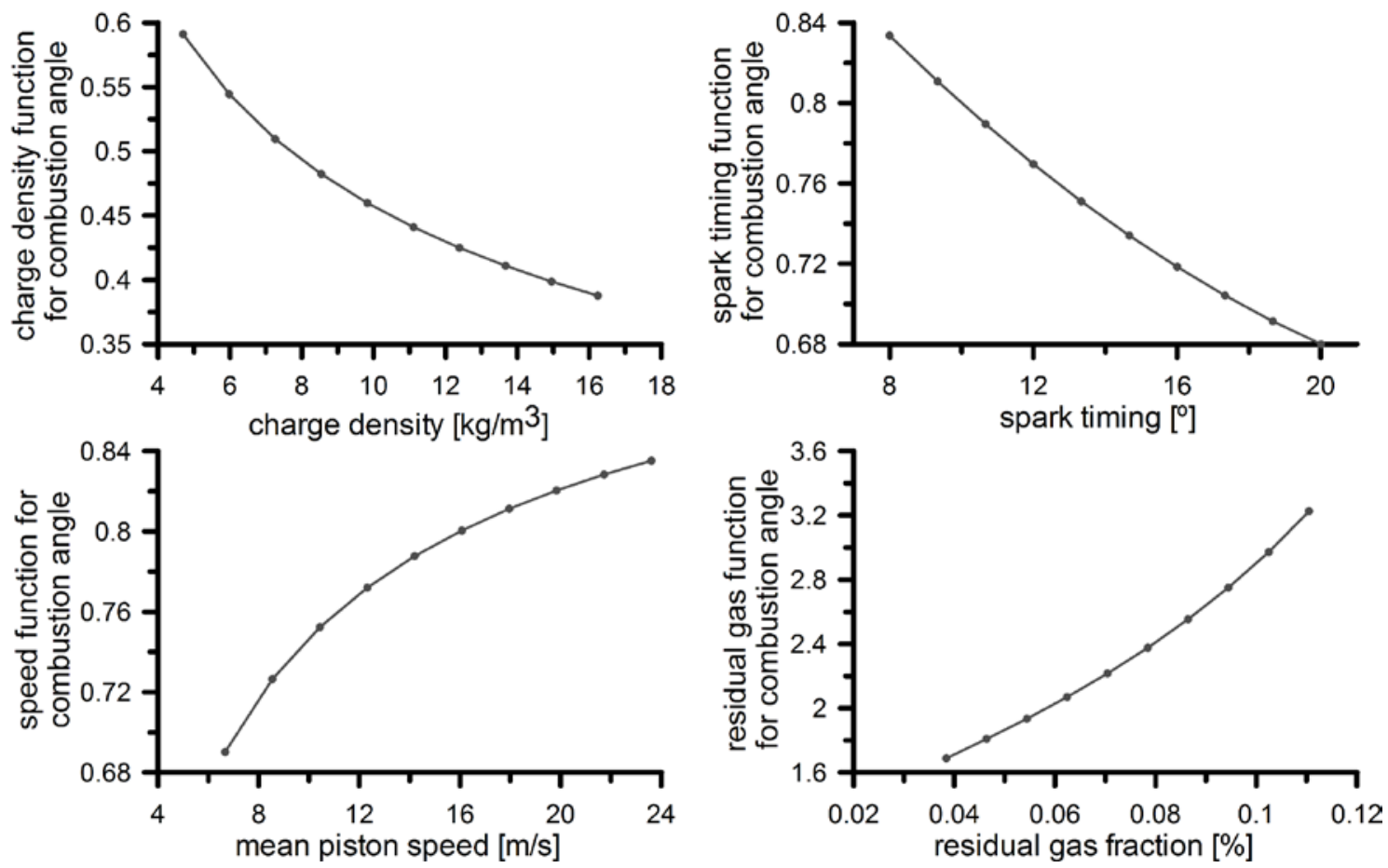

Fig 12. Functions for charge density, mean piston speed, spark timing, and residual gas fraction, used to predict combustion angle. 